\section{International Scientific Journal Theoretical \& Applied Science}

\author{
p-ISSN: 2308-4944 (print) e-ISSN: 2409-0085 (online) \\ Year: 2017 Issue: 11 Volume: 55 \\ Published: $16.11 .2017 \quad \underline{\text { http://T-Science.org }}$
}

\author{
Abdinazar T. Nurmanov \\ Doctor of Science, \\ Tashkent State Pedagogical University, \\ Uzbekistan \\ anurmanovjizzax@mail.ru \\ Asatulla A. Mustafaqulov \\ Tashkent State Pedagogical \\ University, Uzbekistan \\ amustafaqulov@mail.ru
}

SECTION 21. Pedagogy. Psychology. Innovations in the field of education

\title{
ABOUT IMPROVEMENT OF PROCESS OF PREPARATION OF PEDAGOGICAL STAFF IN THE CONDITIONS OF TOTAL QUALITY MANAGEMENT
}

\begin{abstract}
The article is devoted to some questions of improvement of preparation of pedagogical personnel on the basis of the introduction of the higher educational institutions of theory and practical results of the total quality management.

Key words: TQM, total quality management, quality of education, quality management system.

Language: Russian

Citation: Nurmanov AT, Mustafaqulov AA (2017) ABOUT IMPROVEMENT OF PROCESS OF PREPARATION OF PEDAGOGICAL STAFF IN THE CONDITIONS OF TOTAL QUALITY MANAGEMENT. ISJ Theoretical \& Applied Science, 11 (55): 26-33.

Soi: $\underline{\text { http://s-o-i.org/1.1/TAS-11-55-5 Doi: crossef https://dx.doi.org/10.15863/TAS.2017.11.55.5 }}$

\section{О СОВЕРШЕНСТВОВАНИИ ПРОЦЕССА ПОДГОТОВКИ ПЕДАГОГИ-ЧЕСКИХ КАДРОВ В УСЛОВИЯХ ТОТАЛЬНОГО МЕНЕДЖМЕНТА КАЧЕСТВА}

Аннотация: Данная статья посвящена некоторым вопросам совершенствования подготовки педагогических кадров на основе внедрения в высших образовательных учреждениях теории и практических результатов всеобщего менеджмента качества.

Ключевые слова: ТQМ, всеобщий менеджмент качества, качество образования, управление качеством образования, система менеджмента качества.
\end{abstract}

\section{Введение.}

Одной из ведущих мировых тенденций современного образования является обеспечение качества подготовки специалистов в высших образовательных учреждениях. Обеспе-чение качества подготовки специалистов является сегодня главной целью деятельности и политики международных организаций, в частности ООН. В документе «Реформа и развитие высшего образования» отмечается, что соответствие требованиям современности, качество и интернационализация являются основными направлениями деятельности данной организации на местном, национальном и международном уровнях $[1,8]$.

Проблемы качества сегодня находятся в центре внимания участников Болонского процесса. Главная задача европейского высшего образования состоит в сохранении и обеспечении требуемого качества профессиональной подготовки специалиста и поиске механизмов его повышения.

В государственной образовательной политике нашей республики с первых лет независимости особое внимание уделяется качеству подготовки специалистов в высших образова-тельных учреждениях. В условиях интеграции Узбекистана в мировое образовательное сообщество значительно активизировался поиск путей повышения качества образования, создания надежных средств, методов и технологий контроля и оценивания результатов, соотносимых с международными стандартами.

В Постановлении Президента Республики Узбекистан «О мерах по дальнейшему развитию системы высшего образования» [2,c.1] отмечается, что повышение качества и эффективности деятельности высших образовательных учреждений на основе 
внедрения международных стандартов обучения и оценки качества преподавания, стимулирование научно-исследовательской и инновациионной деятельности, создание эффек-тивных механизмов внедрения научных и инновационных достижений в практику, являются стратегическими задачами государства и общества на ближайшие годы.

В годы независимости в Узбекистане для повышения качества подготовки специалистов приняты следующие стратегические документы:

1.Закон Республики Узбекистан «Об образовании»;

2.Закон Республики Узбекистан «О национальной программе подготовки кадров»;

3.Закон Республики Узбекистан «О государственной молодёжной политике»;

4.Государственная программа развития школьного образования Республики Узбекистан на 2004-2009 годы;

5.Государственная программа по осуществлению целей устойчивого развития в Республике Узбекистан на 2016 - 2030 годы;

6.Стратегия действий по дальнейшему развитию Республики Узбекистан в 2017-2021 годах;

7. Постановление Президента Республики Узбекистан «О мерах по дальнейшему развитию системы высшего образования» от 20 апреля 2017 года. Народное слово. 21 апреля 2017 года, № 79 (6743);

8.Постановление Кабинета Министров Республики Узбекистан «Об организации деятельности государственной инспекции по надзору за качеством образования при Кабинете Министров Республики Узбекистан» от 18 июля 2017 года № 515.

\section{Обзор литературы.}

Анализ опыта зарубежных развитых стран в области обеспечения качества подготовки специалистов в высших образовательных учреждениях показывает, что их усилия в настоящее время обращены к решению следующих вопросов:

разработка и внедрение систем качества на основе принципов и рекомендаций тотального управления качеством образования (TQM), включа-ющие рекомендации международных стандартов серии ISO 9000:2000;

разработка общих, универсальных стандартов гарантии качества для Европейских стран (стандарты и директивы для гарантии качества высшего образования Европейской Ассоциации гарантии качества);

разработка и внедрение национальных систем качества образования на основе различных моделей; ориентация и переход с внешнего контроля качества на внутренную самооценку результатов образовательного процесса, что признается более эффективным направлением в данной сфере.

В современных условиях фундаментализации, профессионализации, стандартизации и технологизации высшего образования республики, модернизации его на основе передового мирового и отечественного образования, развития нормативно-правовой базы, реализации компетентностного подхода, совершенствование системы подготовки педагогических кадров может быть достигнуто при эффективном управлении качеством подготовки педагогических кадров, для чего необходимо создание определенных организационно-педагогических условий: научное обоснование и дидактическое обеспечение процесса управления качеством подготовки педагогических кадров, совершенствование организационных и технологических процессов управления качеством подготовки педагогических кадров в высших образовательных учреждениях, учет особенностей педагогической деятельности, специфики подготовки и деятельности педагогических кадров при построении и реализации моделей и технологий управления качеством их подготовки, проведение диагностики и оценки качества подготовки педагогических кадров с использованием международных стандартов, критериев и показателей оценки качества преподавания, совершенствование организационно-управленческих, профессиональных, психологопедагогических способностей и качеств руководящего и научно-педагогического состава педагогических вузов как субъектов управления качеством подготовки педагогических кадров, целенаправленность и системность управления качеством подготовки педагогических кадров.

Совершенствование процесса подготовки педагогических кадров на основе внедрения принципов и методов всеобщего менеджмента качества (ТQM) осуществляется по следующим направлениям управления качеством подготовки педагогических кадров:

планирование качества с учетом социального заказа государства, общества и личности (абитуриенты, студенты, преподаватели, управленческий аппарат, заказчик). Необходимо планировать обязанности всех субъектов этого процесса в непосредственном обеспечении качества;

объединение усилий всех субъектов педагогического взаимодействия для повышения качества подготовки педагогических кадров в содержании, методах и формах, средствах и технологиях организации образовательно- 
воспитательного процесса, разрабатке и совершенствовании показателей качества;

усовершенствование процесса подготовки педагогических кадров на основе организации постоянного контроля качества посредством современных международных стандартов оценки качества преподавания для обеспечения показателей качества, корректировки процесса в соответствии с заданными стандартами;

улучшение качества на основе создания инфраструктуры для непрерывного усовершенствования учебно-воспитательного процесса в педвузе, выявления его недостатков, создания структурных подразделений для реализации предложений и мероприятий по улучшению качества образовательного процесса, обеспечения мотивации участников подготовки, установления контроля за достижением целей, обеспечения коррекции процесса подготовки.

По рекомендациям специалистов [3], исследующих данный вопрос, внедрение принципов TQM в вузе должна включать выполнение следующих задач:

принятие решения руководством вуза о проведении работ по внедрению ТQМ-подхода в управление качеством подготовки педагогических кадров;

разработка стратегии всеобщего управления качеством в вузе (определение политики, целей и задач вуза, показателей качества);

создание совета по качеству и назначение должностных лиц, ответственных за качество в вузе и подразделениях;

распространение информации о внедрении TQM-подхода в вузе и тех преимуществах, которые будут получены после проведения всего комплекса работ;

разработка систем нормативно-правового обеспечения, контроля и отчетности, информированности и ответственности;

разработка руководства по качеству, методических рекомендаций по всем процессам организации, рабочих инструкций для каждого сотрудника вуза;

реорганизация структуры управления вуза в связи с внедрением СМК;

определение основных направлений для улучшения качества и т.д.

Одним из первоочередных задач внедрения TQM-подхода в образовательных учреждениях является создание модели организационной структуры системы управления вузом. В настоящее время в практике вузов применяются следующие модели систем качества [4]: 1) модель системы менеджмента качества в соответствии с требованиями ИСО 9001-2008; 2) модель конкурса Рособрнадзора и Рособразования «Внутриву-зовские системы обеспечения качества подготовки специалистов»; 3) модель
Правительства РФ в области качества; 4) модель Европейского фонда по менеджменту качества (EFQM) и ее модификации для высшего образования; 5) стандарты и директивы гарантии качества Высшего образования в Европейском регионе (ENQA); 6) типовая модель системы качества образовательного учреждения.

Опыт лучших университетов мира в создании системы менеджмента качества позволяет выбрать за основу типовую модель управления качеством в педагогическом вузе, как наиболее эффективную систему на основе рекомендаций и принципов тотального управления качеством образовательного процесса.

Важнейшим направлением совершенствования системы подготовки педагогических кадров является разработка и внедрение научно обоснованных критериев и показателей эффективности управления качеством подготовки специалистов в педвузе.

В научно-педагогической литературе в качестве критериев эффективности управления качеством подготовки педагогических кадров приводятся содержание образовательных программ, результативность обучения и воспитания, результативность методической работы, профессиональная компетентность руководящего и научно-педагогического состава, результативность научной работы, успешность деятельности выпускников педагогических вузов.

К таким критериям также относятся конструктивность модели СМК, эффективность технологии управления качеством подготовки, компетентность руководителей и научнопедагогических кадров в вопросах управления качеством подготовки, психолого-педагогическое сопровождение управления качеством подготовки в вузе, информационное, материально-техническое, финансовое обеспечение управления качеством подготовки и т.д.

В оценке эффективности образовательной деятельности вуза главными объектами являются содержание учебных планов, программ, распределение учебного времени, технологии, методы и средства обучения, а также конечные результаты процесса обучения: знания, умения и навыки, полученные студентами, сформированные компетенции в результате их самостоятельного обучения и самообразования, что является одной из основополагающих идей современного образования [5].

Внедрение технологий на основе рекомендаций и принципов тотального управления качеством образовательного процесса в педвузе предполагает наличие в системе внутренного мониторинга следующих критериев оценки результатов обучения студентов: 
наличие системы внутреннего мониторинга качества знаний в разрезе: студент, специальность, курс, факультет;

результаты текущего, промежуточного и итогового контрольев и аттестации знаний студентов в целом;

наличие предлагаемых и утвержденных вузом стандартизированных тестов по образовательным программам;

наличие исследовательских работ, выполненных студентами (рефератов, курсовых работ, выпускных квалификационных работ и проектов), оценка их качества;

результаты промежуточного государственного контроля;

результаты итоговой государственной аттестации (оценка качества выпускных квалификационных работ и проектов).

Целью внутривузовской системы контроля является соблюдение требований ГОС и других регламентирующих документов, предупреждение, выявление и устранение недостатков, обобщение и распространение передового опыта, поиск резервов улучшения процессов.

Систематическое повышение уровня качества подготовки педагогических кадров важное условие дальнейшего развития и конкурентоспособности высшего педагогического образования в Узбекистане. В разрабатываемой нами системе менеджмента качества педагогического образования одним из основных компонентов управления качеством является мониторинг всех процессов в педвузе. В международном стандарте по качеству ИСО 9000 мониторинг определяется как слежение, надзор, содержание под наблюдением; измерение или испытание через определенные интервалы времени с целью регулирования и управления [6].

Мониторинг качества процессов в деятельности высших педагогических образовательных учреждений, прежде всего, позволяет систематически повышать эффективность взаимодействия преподавателя и студентов, отслеживать процесс формирования будущего учителя, фиксировать достижения определенных уровней качества и своевременно корректировать проблемы в подготовке студентов.

\section{Материалы и методы.}

В Ташкентском государственном педагогическом университете разработана система критериев оценки деятельности профессорско-преподавательского состава, которая позволяет оценивать степень соответствия качества его профессиональной деятельности по подготовке будущих учителей требованиям государственных образовательных стандартов, учитывать социальный заказ рынка труда и потребности работадателей и студентов, а также определять значимость учебных планов, программ и дисциплин в формировании, развитии и совершенствовании профессиональноличностных качеств выпускников.

Данная система критериев включает показатели по 23 видам профессиональной деятельности современного преподавателя вуза, которые оцениваются по 110 бальной шкале (Таблица 1).

Вместе с тем, следует отметить, что главным недостатком данной системы критериев заключется в ее одностороннем характере. Основное внимание уделяется оценке деятельности профессорско-преподавательского состава вузов, а деятельность студентов, будущих учителей, процессы, связанные с нею, остаются вне поля внимания.

Дествующая рейтинговая система учета, контроля и оценки успеваемости обучемых также носит односторонний характер: в основном она направлена на оценку знаний, умений и навыков студентов. По нашему мнению, качество подготовки специалистов в педагогических вузах должно определяться в большей степени на основе критериев их соответствия современным требованиям рынка труда, работодателей, родителей и самих студентов. Следовательно, нужно разработать систему критериев оценки деятельности и студентов педагогических вузов. Она должна включать критерии оценки не только успеваемости студентов по дисциплинам вузовской подготовки, но и процессы, связанные с формированием и развитием у будущих специалистов личностных качеств.

\section{Заключение.}

Определение политики, целей и задач педагогического вуза в области управления качеством, показателей качества являются одной из основных задач внедрения принципов ТQМподхода. По нашему мнению, такая политика должна проводиться в следующих направлениях: совершенствование системы управления качеством в реализации образовательных программ высшего педагогического образования; непрерывное улучшение качества образовательной деятельности на основе использования модернизированных образовательных технологий и достижений фундаментальных и прикладных научных исследований в учебно-воспитательном процессе; развитие научно-исследовательской работы в педвузе и внедрение ее результатов в практику подготовки педагогических кадров; активное привлечение студентов к научной и инновационной деятельности; систематическое повышение квалификации профессорскопреподавательского состава педагогического 
вуза, в частности в зарубежных университетах и научных центрах; развитие сотрудничества вуза с государственными, общественными и негосударственными организациями, институтами гражданского общества и т.д.

Таблица 1.

Критерии оценки деятельности профессорско-преподавательского состава вуза

\begin{tabular}{|c|c|c|c|}
\hline № & \multicolumn{2}{|l|}{ Виды работы } & $\begin{array}{c}\text { Баллы } \\
\text { За } \\
\text { учебный } \\
\text { год }\end{array}$ \\
\hline I & 1. Преподавательская деятельность & 20 & $\mathbf{0 . 0 0}$ \\
\hline & $\begin{array}{l}\text { 1.1. Степень владения теоретическими знаниями, практическими } \\
\text { умениями, современными тенденциями развития преподаваемой научной } \\
\text { дисциплины (по результатам открытых занятий) }\end{array}$ & 8 & $\mathbf{0 . 0 0}$ \\
\hline 1 & 1.1.1. Степень владения научно-теоретическими основами дисциплины & 2 & \\
\hline 2 & 1.1.2. Обеспечение активности студентов на занятиях & 2 & \\
\hline 3 & 1.1.3. Умение связать тему занятия с практикой & 2 & \\
\hline 4 & 1.1.4. Методическое мастерство в доведении содержания темы до студентов & 2 & \\
\hline II & 1.2. Уровень качества преподавания (по результатам опроса студентов) & 5 & $\mathbf{0 . 0 0}$ \\
\hline 1 & $86-100 \%$ & 5 & \\
\hline 2 & $71-85 \%$ & 4 & \\
\hline 3 & $56-70 \%$ & 3 & \\
\hline 4 & $39-55 \%$ & 2 & \\
\hline 5 & $39 \%$ & & \\
\hline III & $\begin{array}{l}\text { 1.3. Участие студентов в олимпиадах, конкурсах, научных грантах по } \\
\text { направлению (дисциплине) преподавателя }\end{array}$ & 7 & $\mathbf{0 . 0 0}$ \\
\hline 1 & 1.3.1. Подготовка победителя республиканской олимпиады & 2 & \\
\hline 2 & 1.3.2. Подготовка победителя университетской олимпиады & 1 & \\
\hline 3 & $\begin{array}{l}\text { 1.3.3. За участие ученика в конференциях и конкурсах (на основе сертификатов } \\
\text { или дипломов) }\end{array}$ & 2 & \\
\hline 4 & $\begin{array}{l}\text { 1.3.4. За участие ученика в научных грантах и инновационных ярмарках (на } \\
\text { основе сертификатов или почетных грамот) }\end{array}$ & 2 & \\
\hline IV & 2. Методическая работа & 20 & $\mathbf{0 . 0 0}$ \\
\hline & 2.1. Учебники и учебные пособия, опубликованные в течение учебного года & 8 & $\mathbf{0 . 0 0}$ \\
\hline 1 & $\begin{array}{l}\text { 2.1.1. Учебники и учебные пособия, опубликованные только самим автором } \\
\text { единолично (на основе свидетельства или решения Ученого Совета } \\
\text { университета) }\end{array}$ & 3 & \\
\hline 2 & $\begin{array}{l}\text { 2.1.2. За } 2 \text { и более учебника или учебного пособия, опубликованного } \\
\text { единолично (на основе свидетельства или решения Ученого Совета } \\
\text { университета) }\end{array}$ & 4 & \\
\hline 3 & $\begin{array}{l}\text { 2.1.3. За учебник или учебное пособие в соавторстве (на основе свидетельства } \\
\text { или решения Ученого Совета университета) }\end{array}$ & 1 & \\
\hline $\mathbf{V}$ & $\begin{array}{l}\text { 2.2. Степень использования на занятиях компьютера и других } \\
\text { информационно-коммуникационных средств, разработка учебных курсов и } \\
\text { учебно-презентационных материалов }\end{array}$ & 7 & 0.00 \\
\hline
\end{tabular}




\begin{tabular}{|c|c|c|c|c|}
\hline ISRA (India) & $=1.344$ & SIS (USA) & ICV (Poland) & $=6.630$ \\
\hline ISI (Dubai, UAE & $=\mathbf{0 . 8 2 9}$ & РИНЦ $($ Russia $)=0.207$ & PIF (India) & $=1.940$ \\
\hline IF (Australia) & $=0.56$ & ESJI (KZ) & IBI (India) & $=4.260$ \\
\hline IF & $=1.500$ & SJIF $($ Morocco $)=\mathbf{2 . 0 3 1}$ & & \\
\hline
\end{tabular}

\begin{tabular}{|c|c|c|c|}
\hline 1 & $\begin{array}{l}\text { 2.2.1. Создание по преподаваемой дисциплине авторских презентаций, } \\
\text { силлабусов и электронных учебников и степень их внедрения в учебном } \\
\text { процессе }\end{array}$ & $\mathbf{3}$ & \\
\hline 2 & $\begin{array}{lllll}\text { 2.2.2. Степень } & \text { использования } \\
\text { качественных презентаций }\end{array}$ & 2 & \\
\hline 3 & 2.2.3. Уровень владения знаниями и умениями по ИКТ & 2 & \\
\hline VI & $\begin{array}{l}\text { 2.3. Уровень применения в учебном процессе современных педагогических } \\
\text { технологий и передовых методов оценки знаний, умений и навыков } \\
\text { студентов }\end{array}$ & 5 & $\mathbf{0 . 0 0}$ \\
\hline 1 & $\begin{array}{l}\text { 2.3.1. За эффективное использование в учебном процессе современных } \\
\text { педагогических технологий }\end{array}$ & 3 & \\
\hline 2 & $\begin{array}{l}\text { 2.3.2. За эффективное использование современных педагогических технологий и } \\
\text { стандартов при оценке знаний студентов }\end{array}$ & 2 & \\
\hline VII & Воспитательная деятельность & 20 & 0.00 \\
\hline & $\begin{array}{l}\text { 3. Участие со студентами в воспитательных мероприятиях: духовно- } \\
\text { просветительская работа, спортивные клубы, научно-творческие кружки, } \\
\text { культурные мероприятия и т.д. }\end{array}$ & 5 & $\mathbf{0 . 0 0}$ \\
\hline 1 & 3.1. Участие со студентами в воспитательных мероприятиях & $\mathbf{1}$ & \\
\hline 2 & 3.2. Активность по физической культуре и спорту & 1 & \\
\hline 3 & 3.3. Руководство научно-творческими кружками & 2 & \\
\hline 4 & 3.4. Активность в проведении общественных культурных мероприятиях & 1 & \\
\hline VIII & 4. Кураторство в академической группе студентов & 6 & $\mathbf{0 . 0 0}$ \\
\hline 1 & 4.1. Выполнение плана куратора группы на учебный год полностью & $\mathbf{2}$ & \\
\hline 2 & 4.2. Участие в конкурсе «Лучший куратор года» & $\mathbf{1}$ & \\
\hline 3 & 4.3. Посещаемость занятий студентами академической группы на 95 \% и выше & 1 & \\
\hline 4 & $\begin{array}{l}\text { 4.4. Эффективность организации в группе мероприятий по профилактике } \\
\text { правонарушений. }\end{array}$ & 2 & \\
\hline IX & 5. Участие в организации свободного времени и досуга студентов & 5 & $\mathbf{0 . 0 0}$ \\
\hline 1 & $\begin{array}{l}\text { 5.1. Подготовка студентов в свободное от занятий время } \\
\text { конкурсам, творческим выставкам, тренингам и соревнованиям }\end{array}$ & 1 & \\
\hline 2 & 5.2. Проведение воспитательной работы в студенческом общежитии по плану & 2 & \\
\hline 3 & 5.3. Работа со студентами, проживающими в частных квартирах & 2 & \\
\hline $\mathbf{X}$ & 6. Общественная работа и работа вне вуза & 4 & $\mathbf{0 . 0 0}$ \\
\hline 1 & 6.1. Участие в выполнении Государственной программы года & 2 & \\
\hline 2 & $\begin{array}{l}\text { 6.2. Общественная деятельность вне вуза (волонтёрская работа, выступление на } \\
\text { страницах печати, работа по трудоустройству выпускников вуза) }\end{array}$ & 2 & \\
\hline XI & Научная деятельность & 30 & \\
\hline & 7. Участие в научных конференциях & $\mathbf{5}$ & $\mathbf{0 . 0 0}$ \\
\hline 1 & $\begin{array}{l}\text { 7.1. Непосредственное участие в международных конференциях с публикацией } \\
\text { статьи }\end{array}$ & 2 & \\
\hline 2 & $\begin{array}{l}\text { 7.2. Непосредственное участие в республиканских конференциях с публикацией } \\
\text { статьи }\end{array}$ & 1 & \\
\hline 3 & Две статьи и более & 1.5 & \\
\hline 4 & Одна статья & $\mathbf{1}$ & \\
\hline 5 & Одна статья зарубежная & 0.7 & \\
\hline 6 & Две и более статьи в местных конференциях & 0.5 & \\
\hline 7 & Одна - местная & 0.3 & \\
\hline 8 & 7.3.Участие в организации конференции & 0.3 & \\
\hline XII & $\begin{array}{l}\text { 8. Публикация материалов, монографий в научных изданиях (в том числе и } \\
\text { в зарубежных научных изданиях) }\end{array}$ & $\mathbf{5}$ & $\mathbf{0 . 0 0}$ \\
\hline 1 & Монографии: & 2 & \\
\hline 2 & Монографии: опубликованы & 2 & \\
\hline 3 & Монографии: рекомендованы к публикации & 1 & \\
\hline 4 & За научные статьи в зарубежных научных журналах: & 2 & \\
\hline 5 & С импакт фактором & 2 & \\
\hline 6 & Другие издания & 1 & \\
\hline 7 & Статьи в журналах, рекомендованных ВАК Республики Узбекистан & 1 & \\
\hline
\end{tabular}

ISPC Technological development,

Philadelphia, USA 


\begin{tabular}{|c|c|c|c|}
\hline 8 & Статьи в журналах, рекомендованных ВАК Республики Узбекистан: две и более & 1 & \\
\hline 9 & Статьи в журналах, рекомендованных ВАК Республики Узбекистан: одна статья & 0.5 & \\
\hline XIII & $\begin{array}{l}\text { 9.Руководство международными научными проектами, хозяйственными } \\
\text { договорами или участие в них }\end{array}$ & 5 & $\mathbf{0 . 0 0}$ \\
\hline 1 & $\begin{array}{l}\text { 9.1. За руководство международными научными проектами, хозяйственными } \\
\text { договорами или участие в них }\end{array}$ & 2 & \\
\hline 2 & 9.1. За подготовку проекта и за участие в конкурсе & 1 & \\
\hline 3 & 9.2. За руководство проектом, хозяйственными договорами в республике & 2 & \\
\hline 4 & 9.3. За участие в проектах, хозяйственных договорах в республике & 1 & \\
\hline \multirow[t]{2}{*}{ XIV } & 10. Патенты и изобретения & 5 & $\mathbf{0 . 0 0}$ \\
\hline & Владение патентами за изобретения и сертификатами за полезные модели: & 3 & \\
\hline 1 & $\begin{array}{l}\text { Единоличное владение патентами за изобретения и сертификатами за полезные } \\
\text { модели }\end{array}$ & 3 & \\
\hline 2 & $\begin{array}{l}\text { Владение патентами за изобретения и сертификатами за полезные модели в } \\
\text { соавторстве с одним соавтором }\end{array}$ & 2 & \\
\hline 3 & $\begin{array}{l}\text { Владение патентами за изобретения и сертификатами за полезные модели в } \\
\text { соавторстве с двумя и более соавторами }\end{array}$ & 1 & \\
\hline $\mathbf{X V}$ & 10.2. Наличие сертификата за программные продукции & 2 & \\
\hline 1 & $\begin{array}{l}\text { 10.2. Наличие сертификата за программные продукции единолично, без } \\
\text { соавторов }\end{array}$ & 2 & \\
\hline 2 & $\begin{array}{l}\begin{array}{l}\text { 10.2. Наличие сертификата } \\
\text { соавторстве }\end{array} \\
\text { за программные }\end{array}$ & 1 & \\
\hline 3 & 10.2. За участие и сдачу документов в конкурс & 0.5 & \\
\hline XVI & $\begin{array}{l}\text { 11. Научное руководство диссертациями докторантов, старших научных } \\
\text { сотрудников }\end{array}$ & 5 & $\mathbf{0 . 0 0}$ \\
\hline 1 & 11.1. Количество докторантов 1 & 1 & \\
\hline 2 & 11.2.Количество докторантов 2 и более & 2 & \\
\hline 3 & 11.3. Защита диссертации докторантов & 2 & \\
\hline XVII & 12. Проведение исследования над докторской диссертацией & 5 & 0.00 \\
\hline 1 & 12.1. Защита докторской диссертации & 5 & \\
\hline 2 & $\begin{array}{l}\text { 12.2. Объявление темы докторской диссертации на сайте Комитета по науке и } \\
\text { технологиям, в бюллетени ВАК }\end{array}$ & 1 & \\
\hline 3 & $\begin{array}{l}\text { 12.3. Выполнение } \text { индивидуального } \\
\text { диссертации }\end{array}$ & 1.5 & \\
\hline 4 & 12.4. Сдача квалификационных экзаменов & 0.5 & \\
\hline \multirow[t]{2}{*}{ XVIII } & Личный вклад в развитие ВУЗа & $\mathbf{1 0}$ & $\mathbf{0 . 0 0}$ \\
\hline & $\begin{array}{l}\text { 13. Участие в усилении сотрудничества ВУЗа с академическими лицеями, } \\
\text { колледжами (преподавательская деятельность и организация тренингов) }\end{array}$ & 3 & 0.00 \\
\hline 1 & $\begin{array}{l}\text { 13.1. Участие в усилении сотрудничества ВУЗа с вузами, академическими } \\
\text { лицеями, колледжами, общеобразовательными школами, создание для них } \\
\text { учебной литературы и электронных учебных ресурсов }\end{array}$ & 1 & \\
\hline 2 & $\begin{array}{lllll}\begin{array}{l}\text { 13.2. } \\
\text { обабота по по совместительству }\end{array} \text { в } & \text { средних, } & \text { средне-специальных } \\
\end{array}$ & 2 & \\
\hline XIX & 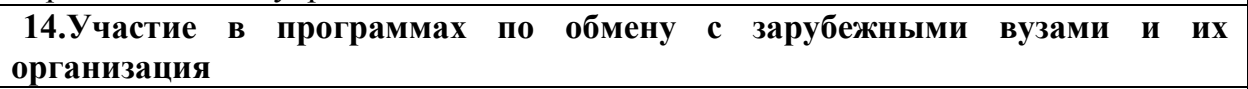 & 4 & 0.00 \\
\hline 1 & 14.1. За организацию программ по обмену с зарубежными вузами & 2 & \\
\hline 2 & 14.2. За участие в программах по обмену с зарубежными вузами & 2 & \\
\hline $\mathbf{X X}$ & $\begin{array}{l}\text { 15. Участие в открытии нового направления, новой кафедры, лаборатории, } \\
\text { участие в пополнении электронной базы информационного центра }\end{array}$ & 3 & 0.00 \\
\hline 1 & 15.1. Участие в открытии нового направления, новой кафедры, лаборатории & 1 & \\
\hline 2 & $\begin{array}{l}\text { 15.2. Участие в пополнении электронной базы информационно-ресурсного } \\
\text { центра }\end{array}$ & 2 & \\
\hline \multirow[t]{2}{*}{ XXI } & Личные достоинства & 10 & \\
\hline & 16. Научная степень и научное звание & 3 & $\mathbf{0 . 0 0}$ \\
\hline 1 & 16.1. Доктор наук со званием & 3 & \\
\hline 2 & 16.2. Кандидат наук со званием, доктор наук без ученого звания & 2 & \\
\hline 3 & 16.3. Кандидат наук & 1 & \\
\hline
\end{tabular}




\begin{tabular}{|c|c|c|c|}
\hline XXII & 17. Повышение квалификации & 2 & $\mathbf{0 . 0 0}$ \\
\hline \multirow[t]{2}{*}{1} & Повышение квалификации (сертификат) & 2 & \\
\hline & $\begin{array}{l}\text { 18. Владение иностранными языками, разработка материалов на } \\
\text { иностранных языках и использование их в практике преподавания } \\
\text { дисциплин }\end{array}$ & 2 & 0.00 \\
\hline 1 & 18.1. Знание иностранного языка & 1 & \\
\hline 2 & $\begin{array}{l}\text { 18.2. Разработка материалов на иностранных языках и использование их в } \\
\text { практике преподавания дисциплин }\end{array}$ & 1 & \\
\hline XXIII & 19. Стажировка в зарубежных вузах и научных центрах & 3 & $\mathbf{0 . 0 0}$ \\
\hline 1 & 19.1. Стажировка в зарубежных вузах и научных центрах & 2 & \\
\hline 2 & 19.2. В вузах СНГ & 1 & \\
\hline \multirow[t]{2}{*}{3} & 19.3. Организация семинаров по результатам стажировки & 1 & \\
\hline & Всего: & 110 & \\
\hline
\end{tabular}

\section{References:}

1. (1995) Reforma i razvitie vysshego obrazovaniya. Programmnyj dokument.Yunesko.-1995.

2. (2017) Postanovlenie Prezidenta Respubliki Uzbekistan «O merax po dalnejshemu razvitiyu sistemy vysshego obrazovaniya» ot 20 aprelya 2017 goda. Narodnoe slovo. 21 aprelya 2017 goda, № 79 (6743).

3. (2011) Upravlenie kachestvom v vysshem uchebnom zavedenii / G.M. Mutanov, A.K. Tomilin, Ju.E.Kukina i dr. - Ust-Kamenogorsk: vkgtu, 2011. - 116 p.

4. Bonyushko N.A., Tumanov K.M. (2008) Strategiya formirovaniya sistemy menedzhmenta kachestva vuza // Standarty i kachestvo. №9.

5. Potashnik M.M. (2011) Eksklyuzivnye aspekty upravleniya shkoloj: metodicheskoe posobie/m.m. potashnik.-M.: pedagogicheskoe obshhest-vo rossii,-320p.

6. Zelenskaya N.V. (2008) Pedagogicheskaya koncepciya upravleniya kachestvom podgotovki oficerskix kadrov. Avtor. dis...d.p.n., M.:-31 p.

7. (2009) Higher Education in Europe 2009: Developments in the Bologna Process.EACEA, March 2009. Available: http://www.eurydice.org (Accessed: 10.11.2017).

8. (2009) The Bologna Process 2020 - The European Higher Education Area in the new decade- Communiqué of the Conference of European Ministers Responsible for Higher Education, Leuven and Louvain-la-Neuve, 2829 April 2009.

9. (2017) ENQA - Available: http://www.enqa.eu/ (Accessed: 10.11.2017).

10. (2017) EQAR - European Quality Assurance Register in Higher Education - Available: http://www.eqar.eu/ (Accessed: 10.11.2017).

11. (2017) EUA - Available: http://www.eua.be/index.php (Accessed: 10.11.2017). (Navigate menu to 'Quality Assurance'. Many links to other resources.) ESG, 2015. 